never studied at Paris or elsewhere? Nor are the Apostles said to have gone to a University . . . . The larger apparent size of heavenly bodies when near the horizon than when in the zenith is compared to the increasing humility of heavenly-minded men as they rise in worldly dignity, and in treating of the diseases of the eye, a squint is compared to envy and inflammation to anger."

The moral tone which pervades the treatise is ascetic. The saint is praised who, on losing the sight of one eye, told his friends not to mourn, for of two enemies he had lost one. Chastity is extolled in the strongest terms; the author is obviously a man for he throws all the blame in this matter on the opposite sex.

The question of authorship of this book is an interesting point. Both Grosseteste and Peckham were of humble birth, both were outspoken champions of the Church and of morality. Of the two, I think that Peckham protested more against pluralities than Grosseteste. Both probably knew enough about optics to have written it, though it is generally held at the present time to be of a later date than that of Grosseteste.

\title{
A CASE OF UVEO-PAROTID FEVER
}

$$
\text { BY }
$$

H. KaITZ

LIVER POOL

UVEO-PAROTID fever is a rare clinical condition characterized by parotitis, uveitis, a mild fever, enlargement of the salivary glands and lymphatic nodes, and occasionally cerebro-spinal nerve palsies.

There is a diversity of opinion as to whether the tubercle bacillus is the aetiological agent. In one case reported in the literature the post-mortem examination revealed evidence of miliary tuberculosis.

\section{Case report.}

A female patient, aged 24 years, was admitted to St. Paul's Eye Hospital, Liverpool, on September 18, 1930, with the following history :

April, 1930. The patient felt "run down" and "out of sorts." She had lost weight and -had no appetite. These symptoms continued until May (1930), when her mother noticed that each side of the patient's face was swollen. The temperature was taken each morning and for several weeks remained in the region of $101^{\circ} \mathrm{F}$. This condition was regarded as " mumps." There was also enlargement of the cervical lymphatic nodes. 
As no improvement followed, the patient was sent to a consulting surgeon, who ordered deep X-ray therapy for the parotid glands. After this treatment the parotid swellings diminished appreciably, but during the course of this therapy the patient noticed that her " eyes became bad." There was mistiness of vision and "black spots." She was referred to an ophthalmic surgeon, who advised admission to hospital.

On admission the girl was noted to be pale, with perhaps a slight hectic flush. No obvious loss of weight was noticed. There were many carious teeth, but a clean throat. There were obvious parotid swellings, the left was the larger; the right pre-auricular lymph node was easily palpable; she had bilateral sub-maxillary and cervical glandular enlargement; these felt shotty and were discrete. No enlargement of the axillary glands was present.

Chest. She was thought to have slight consolidation of her right apex; diminished Kronig's area and increased voice sounds with diminished breath sounds. The patient was seen by the consulting physician, who reported " no signs of pulmonary tuberculosis."

X-ray of chest reported " Chronic inflammatory changes only." Heart, sounds clear.

Abdomen. Nil abnormal.

C. N.S. No paresis of any cerebro-spinal nerve (in contrast to Heerfordt's description). ${ }^{2}$ Knee jerks, brisk. (Compare Souter's case, in which they were absent). ${ }^{1}$

Temperature. During the first part of her stay in hospital the curve remained normal but recently has risen to $99.8^{\circ} \mathrm{F}$. especially towards evening.

Urine. Normal.

Eye Condition. Right vision $=6 / 36$, no improvement on subjective testing. Left vision $=6 / 60$, no improvement on subjective testing.

Right Eye. Active irido-cyclitis; much " mutton fat" K.P. which was slightly more scattered than the usual typical inferior triangular limitation; the K.P. was tending to coalesce into larger blebs; extensive posterior synechiae; pupil moderately contracted (after atropine); retrolental space not seen with slit-lamp. Ophthalmoscope revealed hazy vitreous; disc margins were blurred, giving the suggestion of papilloedema.

Left Eye. Much " mutton fat" K.P. confined to the inferior triangular limitation; the K.P. was tending to coalesce into larger spots.

Ophthalmoscope. Blurring of disc edges with the suggestion of papilloedema-but probably due to local exudates.

Lacrimal glands. Not palpable.

Wassermann Reaction. Negative. 
Von Pirquet. Not done; modern opinion seems to suggest that the test only serves to confuse the issue in deciding as to whether an eye infection is tuberculous in nature, although it is of help as a guide to treatment. ${ }^{3}$ Souter's case ${ }^{1}$ gave a negative reaction even though the post-mortem revealed gross general tuberculous disease.

25. 9. 30. Lumbar Puncture. Moderate pressure; fluid clear; protein, normal ; cells, 2 per c.mm.; sugar, 64 mgrms. per cent.; chlorides, 741 mgrms. per cent.; gold curve negative throughout series; Wassermann Reaction, completely negative, i.e., fluid was normal in all respects.

29. 9. 30. Blood. "Haemoglobin 85 per cent.; red cells $4,840,000$; size-halometer $=7 \cdot 17$, i.e., normal; white cells $=$ 4,$688 ;$ polymorphs $=54.5$ per cent.; lymphocytes $=27.5$ per cent.; monocytes $=8.5$ per cent.; eosinophils $=8.0$ per cent.; basophils $=1.5$ per cent. ; platelets $=361,000$.

Stained films showed no abnormality of red or white cells, and no immature cells were seen. As the patient was afebrile, a blood culture was not done. The above blood-picture is interesting, but cannot be said to throw any light on the condition. It is even possible that it is the result of X-rays.

28. 9. 30. The parotid swellings have practically disappeared; cervical lymph nodes are less easily palpable and have lost their " discrete individuality."

The Eye Condition is in statu quo; there being still very marked ciliary injection.

The girl feels very well in herself and is anxious to return home.

Conclusions. The above history fits in with the rare clinical entity of uveo-parotid fever.

One is struck by the complete absence of positive evidence of active tuberculous infection; the history of a discharging left cervical gland (which had been lanced) might suggest a tuberculous infection.

There is also no record of a facial nerve palsy, the presence of which is regarded as typical by Heerfordt. ${ }^{2}$

And finally, there is good general improvement and gradual quiescence of fever.

In conclusion, I wish to thank Mr. Eldon Gorst, the Honorary Surgeon of St. Paul's, for his kind help and suggestions; and also Dr. Howell-Evans for his laboratory assistance.

\section{REFERENCES.}

1. Souter.-Trans, Ophthal. Soc. U,K., 1929.

2. Heerfordt.-Arch.f. Ophthal., LXX, 1909.

3. Browning, S.. H.-Trans. Ophthal. Soc. U.K., 1929. 